\title{
An uncommon case of acute lower limb ischemia
}

\author{
Maria Viviana Carlino, ${ }^{1}$ Paola Ieranò, ${ }^{1}$ Mario Venafro, ${ }^{1}$ Claudia Sara Cimmino, ${ }^{1}$ Costantino Mancusi, ${ }^{2}$ \\ Francesco Lassandro, ${ }^{3}$ Piero Angelini, ${ }^{4}$ Alfonso Sforza, ${ }^{1}$ Mario Guarino ${ }^{1}$ \\ ${ }^{1}$ Emergency Department, C.T.O. Hospital, Naples; ${ }^{2}$ Hypertension Research Center, Federico II University, Naples; ${ }^{3}$ Department \\ of Radiology Monaldi Hospital, Naples; ${ }^{4}$ Department of General Surgery, Monaldi-C.T.O. Hospital, Naples, Italy
}

\begin{abstract}
We describe a case of a 76-year-old woman who presented to the Emergency Department with right lower limb pain after a fall. One hour after the admission to the Emergency Department, the patient presented all the signs and symptoms of acute limb ischemia. The patient underwent contrast-enhanced computed tomographic scan of abdomen and right lower limb that showed a large abdominal lesion suggestive of ovarian cancer compressing the right common iliac artery and a visible thrombus and ruptured plaque in this artery. We hypothesized that the acute limb ischemia caused by thrombosis in situ arose from acute plaque rupture probably due to the impact of the large abdominal mass on the artery during patient's fall.
\end{abstract}

\section{Case Report}

A 76-year-old woman presented to the Emergency Department (ED) with right lower limb pain after a fall. She had a history of hypertension. At the time of admission blood pressure was $130 / 80 \mathrm{mmHg}$, heart rate was $70 \mathrm{bpm}$, regular, oxygen saturation was $97 \%\left(\mathrm{FiO}_{2}\right.$ $21 \%$ ) and respiratory rate was 17 breaths/min. Electrocardiogram showed sinus rhythm with normal AV conduction, normal axis and QT interval. The skin color and temperature of the right lower limb were normal. Femur and pelvis radiographies were normal. Results

Correspondence: Maria Viviana Carlino, Ospedale C.T.O. (Azienda Ospedaliera dei Colli), viale Colli Aminei 21, 80141 Naples, Italy.

E-mail: vivianacarlino@yahoo.it

Key words: Abdominal mass; ovarian cancer; emergency department; point-of-care ultrasound.

Contributions: MVC, AS conceived the paper and wrote the manuscript; PI, MV, CSC, CM, FL, PA, MG contributed to the discussion and edited the manuscript.

Conflict of interests: the authors declare no potential conflict of interests.

Received for publication: 2 January 2019.

Revision received: 12 May 2019.

Accepted for publication: 3 June 2019.

This work is licensed under a Creative Commons Attribution NonCommercial 4.0 License (CC BY-NC 4.0).

${ }^{\circ}$ Copyright: the Author(s), 2019

Licensee PAGEPress, Italy

Italian Journal of Medicine 2019; 13:185-186

doi:10.4081/itjm.2019.1131 of blood tests are shown in Table 1. One hour after the admission to the ED, the patient presented all the signs and symptoms of acute limb ischemia; the right lower limb appeared purple with a fine reticular pattern, cold, absent pulses. The patient presented paresthesia and paralysis of the right lower limb.

Point-of-care ultrasound was done, confirming the absence of pulses at the right lower limb and showing a large abdominal mass. She was treated with $5000 \mathrm{UI}$ of unfractionated heparin injected intravenously, infusion of normal saline and $1000 \mathrm{mg}$ of paracetamol. The patient underwent contrast-enhanced computed tomographic scan of abdomen and right lower limb that showed a large abdominal lesion $(18 \times 14 \times 19 \mathrm{~cm})$ suggestive of ovarian cancer (Figure 1) compressing the right common iliac artery and a visible thrombus and ruptured plaque in this artery (Figure 2). The patient underwent an aortofemoral bypass and a resection of the abdominal lesion. Furthermore, the patient underwent laparotomy with ovarian mass resection, hysterectomy and bilateral salpingo-oophorectomy. Mass biopsy confirmed the diagnosis: mucinous cystadenoma of ovary.

\section{Discussion}

Acute limb ischemia is a medical emergency with significant morbidity and mortality. The incidence is estimated to be 1.5 cases per 10,000 persons per year. ${ }^{1}$ Limb ischemia is classified on the basis of onset and severity. Complete acute ischemia will lead to extensive tissue necrosis within six hours unless the limb is surgically revascularised. ${ }^{2}$ Acute limb ischemia can be the result of thrombotic, embolic, inflammatory, traumatic, anatomic or iatrogenic causes. ${ }^{3}$ Acute limb ischemia is caused by embolus ( $30 \%$ of cases) or by acute thrombotic occlusion of a pre-existing stenotic 
arterial segment $(60 \%)^{2}$ that can occur when a vulnerable plaque ruptures and a thrombus forms. ${ }^{3}$

Rupture of atherosclerotic plaque has been identified as the proximate event in the majority of cases of acute ischemic syndromes. Plaque rupture exposes thrombogenic components of the plaque, activating the clotting cascade and promoting thrombus formation. ${ }^{4}$

Blunt trauma in individuals with atheroma can result in subintimal dissection and embolization of plaques or thrombus formation. ${ }^{5}$ In addition, increased intra-abdominal pressure generated during patient's fall may have been transmitted down the blood column in the aorta and then in the right common iliac artery. ${ }^{6}$ The

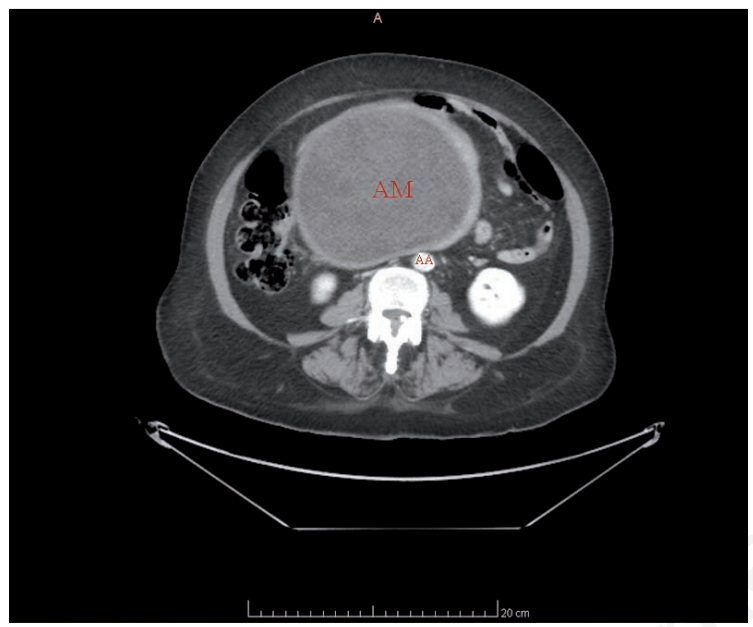

Figure 1. Contrast-enhanced computed tomographic scan: a large abdominal lesion suggestive of ovarian cancer. AM, abdominal mass; AA, abdominal aorta.

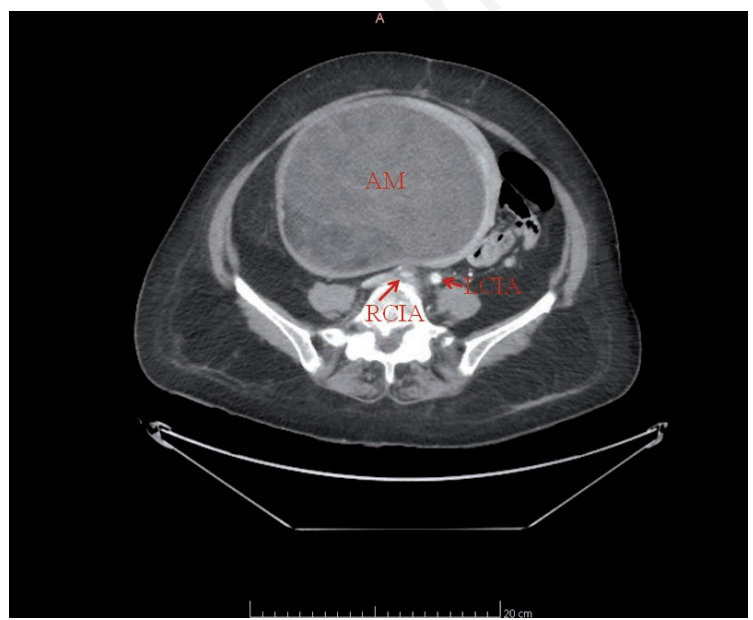

Figure 2. Contrast-enhanced computed tomographic scan: the abdominal lesion compressing the right common iliac artery and a visible thrombus and ruptured plaque in this artery. AM, abdominal mass; LCIA, left common iliac artery; RCIA, right common iliac artery.
Table 1. Laboratory tests.

\begin{tabular}{lcc}
\hline Parameter & Value & Unit of measure \\
\hline Red blood cells & 4.16 & $\times 10^{6} / \mu \mathrm{L}$ \\
\hline Hemoglobin & 12.2 & $\mathrm{~g} / \mathrm{dL}$ \\
\hline Hematocrit & 36.2 & $\%$ \\
\hline Platelets & 318 & $\times 10^{3} / \mu \mathrm{L}$ \\
\hline White blood cells & 12.1 & $\times 10^{3} / \mu \mathrm{L}$ \\
\hline Urea & 50 & $\mathrm{mg} / \mathrm{dL}$ \\
\hline Creatinine & 0.84 & $\mathrm{mg} / \mathrm{dL}$ \\
\hline Aspartate aminotransferase & 23 & $\mathrm{UI} / \mathrm{L}$ \\
\hline Alanine aminotransferase & 22 & $\mathrm{UI} / \mathrm{L}$ \\
\hline Sodium & 139 & $\mathrm{mmol} / \mathrm{L}$ \\
\hline Potassium & 3.7 & $\mathrm{mmol} / \mathrm{L}$ \\
\hline D-dimer & 3409 & $\mathrm{ng} / \mathrm{mL}$ \\
\hline International normalized ratio & 1.13 & \\
\hline
\end{tabular}

hydraulic ram effect caused and associated with the pressure on the artery by the abdominal mass, may have determined the final plaque rupture, resulting in thrombus formation, luminal occlusion and limb ischemia.

We report a case of acute limb ischemia caused by thrombosis in situ arisen from acute plaque rupture probably due to the impact of the large abdominal mass on the artery during patient's fall, this case represents a rare clinical entity described in literature.

\section{Conclusions}

We present a case of acute limb ischemia probably due to the combination of two different physiopathological mechanisms: the trauma determined the right common iliac artery compression by the abdominal mass inducing a thrombosis in situ arisen from acute plaque rupture.

\section{References}

1. Creager MA, Kafman JA, Conte MS. Clinical practice. Acute limb ischemia. N Engl J Med 2012;366:2198-206.

2. Callum K, Bradbury A. ABC of arterial and venous disease. Acute limb ischaemia. BMJ 2000;320:764-7.

3. Santistevan JR. Acute limb ischemia: an emergency medicine approach. Emerg Med Clin North Am 2017; 35:889-909.

4. Shah PK. Mechanisms of plaque vulnerability and rupture. J Am Coll Cardiol 2003;41:15S-22S.

5. Hertzer NR. Peripheral atheromatous embolization following blunt abdominal trauma. Surgery 1977;82:244-7.

6. Beless DJ, Muller DS, Perez H. Aortoiliac occlusion secondary to atherosclerotic plaque rupture as the result of blunt trauma. Ann Emerg Med 1990;922-924:115-7. 